\title{
LA PRECEPTIVA DEL PERFECTO CORTESANO EN CAUTIVERIO FELIZ DE PINEDA Y BASCUÑ̃́N
}

The perfect gentleman in Cautiverio Feliz of Pineda y Bascuñán

\author{
EDUARDO CASTRO RÍOS \\ Universidad de Los Lagos (Chile) \\ ecastro@ulagos.cl
}

\section{Resumen}

Una lectura atenta acerca del Cautiverio Feliz de Pineda y Bascuñán (1982), indudablemente, nos despertaría varias asociaciones, no solo con otras formas de literatura histórica propias de la época, sino que con otras obras de las que integra algunos elementos como: los modos de estructuración discursiva y los modelos o perfiles agenciales. En este sentido, la lectura de la obra de Pineda nos remitiría a El Cortesano de Baltazar Castiglione (1994), por cuanto muchos de los rasgos del perfecto caballero, presentados en El Cortesano, se encuentran insertos en algunos personajes de la obra de Pineda. No es raro encontrar en el Cautiverio, entre otras cosas, las cualidades del perfecto caballero plasmadas en los indígenas, virtudes que adornan también a algunos criollos y españoles antiguos.

Palabras clave: Perfecto cortesano; españoles antiguos; indígenas

Abstract

A close reading to Pineda and Bascuñán's Cautiverio Feliz, undoubtedly, would wake us a series of asociations, not only with other forms of historical literatura from the epoch, but also with other works that integrate some elements such as: kinds of speech structure and kinds of instrumental profiles. In this sense, reading Pineda's work would lead us to Castiglione's $E l$ Cortesano, because many of the characteristic of the perfect gentleman presented in El Cortesano, are inserted in some characters of Pineda's work. It is not strange to find in El Cautiverio, among other things, the qualities of a perfect gentleman, shaped on the natives, virtues, virtues that also adorn some creole and old spaniards.

Key words: Perfect gentleman; old Spaniards; natives

\section{LA PERSPECTIVA DEL PERFECTO CORTESANO}

El presente trabajo tiene por objetivo analizar la filosofía o las teorías que inspiran la construcción del mundo (narrativo, personajes, espacio, acontecimiento) en el Cautiverio Feliz de Pineda y Bascuñán. Y, en el mismo sentido, realizar una aproximación a la misión que esta obra cumple en tanto objeto cultural. Una primera observación al conjunto de rasgos caracterológicos de los personajes y a las modalidades del discurso nos lleva a reconocer que uno de los elementos ideológicos que subyacen en la perspectiva interpretativa de esta obra lo constituye la preceptiva del 


\section{Eduardo Castro Ríos}

perfecto cortesano, la que se encuentra expuesta en el libro El Cortesano de Baltazar Castiglione. Sin embargo, la tipificación de cualidades en este caso no se reduce al simple establecimiento de una taxonomía valórica, sino más bien a la instauración de un sistema categorial necesario en tanto régimen de acreditación dentro de un sistema sociocultural determinado, lo que en Castiglione es codificado en una serie de virtudes morales que hacen posible, a su vez, la realización de funciones sociales y políticas, como decir la verdad o instruir al príncipe en las virtudes para sacarlo de la ignorancia y aconsejarlo en la conducción política del reino, axiomas que se traducen en Pineda en una extensa denuncia de los males que afectan al reino de Chile y en la proposición de la transformación política y social mediante de un nuevo sistema de administración gubernamental para el territorio.

A continuación examinaremos brevemente los contenidos más importantes de la preceptiva del Perfecto Cortesano y veremos cómo esta funciona en el Cautiverio Feliz.

En El Cortesano de Castiglione es el conde Ludovico de Canosa quien junto con otros contertulios expone las cualidades del buen cortesano, durante las pláticas celebradas en la corte del duque Guidubaldo, heredero del duque Federico de Urbino. Los postulados planteados por el conde Ludovico respecto del perfecto cortesano se pueden resumir en las siguientes virtudes:

a) Buen linaje, es decir, nobleza de sangre.

b) Claro ingenio, gentil hombre de rostro y buena disposición del cuerpo.

c) Ser diestro en el uso y el ejercicio de las armas, solo utilizarlas en la defensa de la honra y para servir al rey. Asimismo, jamás el cortesano debe jactarse de sus habilidades guerreras.

d) Hablar y escribir bien, omitiendo toda afectación en sus escritos.

e) Dominar lenguas clásicas, como el griego y el latín.

f) Ornado y ataviado en el ánima como en el cuerpo, es decir, ser un hombre de bien, limpio en sus costumbres y templado en sus acciones.

g) Saber cantar y entender el arte, como el tañer diversos instrumentos.

h) Sus sentimientos amorosos deben tener como fuente de inspiración la hermosura y el amor divino (Castiglione, 1994).

\section{VIRTUDES EN ESPAÑOLES E INDÍGENAS}

Todas estas virtudes, que caracterizan al perfecto cortesano, lo acreditan frente a su señor, permitiéndole guiarlo por el camino del bien y apartarlo de los vicios. Es aquí, en este punto, en donde estos atributos se erigen en las más nobles tareas o funciones que debe cumplir el cortesano, tanto en la relación humana como política que establece ya sea con el soberano o el reino.

En los indígenas esta preceptiva no solo funciona en el tratamiento que estos otorgan a Pineda y Bascuñán durante su cautiverio, sino también en el discurso y en la praxis cotidiana de estos. Maulicán es el amo y captor de Pineda y Bascuñan, es quien le dará protección y amistad, para finalmente devolverlo a su padre a cambio de la 
libertad de otros indígenas principales. La relación de Pineda y Maulicán no será de esclavo a amo, sino que estará marcada por condiciones de igualdad y amparo.

La nobleza de sangre del indígena se manifiesta en primer lugar cuando le promete protegerlo de cualquier peligro y que volverá a su tierra. Esto motivará a Pineda a comparar las cualidades de este indígena con los de su propia condición, dejando en claro que pocos hay con las virtudes de Maulicán: "Gran dicha fue la mía, que me cupiese por suerte el ir sujeto a un hombre noble y cacique principal" (Pineda y Bascuñán, 1982, p.44).

Ancanamón. Sus cualidades de arrogante, discreto y desenfadado son señaladas por Pineda:

Tomó Ancanamón la mano, como dueño del convite, y estuvo grande rato razonando a modo de un sermón entre nosotros, que atentos le miraban los oyentes; porque de verdad el indio era arrogante, discreto y desenfadado (Pineda y Bascuñán, 1982, p.76).

En el caso de Tureupillán, Pineda alude al discurso de despedida que el indio le brinda; lo destaca principalmente por sus dotes de orador y su gran capacidad reflexiva, entre otras cualidades:

Dio principio el venerable viejo a su razonamiento con retórico estilo, sólido, macizo y grave, que con sus varoniles voces y maduros años tenían los oyentes suspensos los sentidos y potencias, y fijos los ojos en sus palabras y blancas canas, que bien parecen en semejantes actos (Pineda y Bascuñán, 1982, p.179).

Posteriormente, en otra parte del discurso se referirá a la importancia de respetar la vida de los cautivos. Rechaza el asesinato a sangre fría y propugna la generosidad del corazón. Concluye su discurso aconsejando al propio Pineda acerca de cómo debiera ser su conducta futura en lo que respecta a la guerra y a sus consecuencias. Recomendándoles especialmente el buen trato a los cautivos y poniéndole como modelo a su propio padre, don Álvaro, sin olvidar jamás el trato recibido durante su permanencia como cautivo.

La nobleza de sangre de los indígenas, por tanto, se demuestra también en el reconocimiento que hacen los caciques Lientur, Colpoche y Huirumanque de las virtudes personales del padre del cautivo. En este sentido el cacique Tureupillán conminará a Francisco de Pineda y Bascuñán con las siguientes palabras:

Imitad a vuestro padre Álvaro, que aunque es tan gran soldado guerrero, y que ha muerto muchos de los nuestros peleando en las batallas, y cobrando tan grande opinión la que le esmalta su valor y su generoso pecho, es el que jamás a sangre fría ha quitado la vida a ningún cautivo, antes se hallan muchos que por su piedad y buen corazón están en sus tierras libres gozando de su quietud y descanso (Pineda y Bascuñán, 1982, p.182-183). 


\section{Eduardo Castro Ríos}

Este paradigma no solo se cumple por ser hijo de un varón notable, sino por la rectitud de sus actos. Junto con demostrar su destreza y valentía en el uso de las armas, habla y escribe con amenidad y sin afectación, en el capítulo primero hay una clara demostración del rechazo al estilo rebuscado en que caían muchos cronistas de la época, menciona:

Solo si podré decir y dar a entender lo que me ha movido a coger la pluma y escribir algunos sucesos de este reino con verdaderas experiencias "aunque con humilde y llano estilo" (Pineda y Bascuñán, 1982, p.19).

Junto con estas cualidades habría que señalar la templanza de sus acciones, la importancia que tuvieron en su formación grandes maestros. La honestidad y la limpieza del alma la que sin duda está ligada a la nobleza de sus sentimientos amorosos $\mathrm{y}$ a su sentido de religiosidad.

\section{LAS FUNCIONES DEL PERFECTO CORTESANO EN ESPAÑOLES E INDÍGENAS}

A partir del cumplimiento de esta preceptiva, Pineda y Bascuñán, se acredita como un perfecto cortesano, por tanto, puede cumplir las siguientes funciones en relación con el monarca y el reino: a) decir la verdad al príncipe. Esto se puede realizar mediante el propósito del libro y con la denuncia de los males que afectan al reino; y, b) aconsejar al monarca en cuanto a la conducción política del reino. Ya sea en la proposición de soluciones transitorias o la total transformación política y social de Chile. En esta perspectiva, la finalidad del Cautiverio no solo será contar, sino también persuadir (Mignolo, 1981, p. 100).

Por tanto, de acuerdo con la primera función, el Cautiverio Feliz se organiza como texto a partir del deseo del autor de decir la verdad, para ello elige dos variables que den la ilusión de verosimilitud a su discurso. La primera, consiste en acreditarse como el perfecto cortesano o caballero, y la segunda tiene que ver con la perspectiva temporal, a partir de esta se relatan los acontecimientos.

El propósito de Pineda de establecer la verdad acerca de la guerra entre españoles e indígenas también funciona como una forma de desmitificar los escritos de otros autores que, guiados por la adulación o el propio interés, carecieron de la objetividad necesaria para referirlos imparcialmente. Otro aspecto que favorece la búsqueda de la verdad por parte de Pineda y Bascuñán es la propia experiencia como prisionero de los indígenas, lo que le permitirá conocerlos desde dentro, en sus virtudes y defectos.

De este modo, el Cautiverio Feliz se instaurará como un discurso refutatorio fundado en la elocuencia legítima. Sus afirmaciones o refutaciones ganarán en verosimilitud al estar avaladas por su propia experiencia como soldado y cautivo, a diferencia de la crónica oficial, sustentada en la adulación y el interés egoísta. No es de extrañar entonces, su dureza ante la crónica oficialista. 
Es por ello que condena explícitamente lo que podríamos llamar "adulación por encargo", entendiendo por tal la exaltación de determinadas figuras, como una forma de conseguir favores o dineros, en desmedro de los que realmente merecían ser destacados por sus méritos personales, tanto en la guerra como en su vida personal.

Afirmado en su propósito de "decir la verdad", Pineda y Bascuñán procederá a realizar tan noble función por medio de la denuncia de los males del reino y la asunción de la defensa del indígena. En consecuencia, procederá a denunciar la tiranía, la inhumanidad, la codicia y otros delitos cometidos por los conquistadores, asimismo, pone en evidencia la falta de consecuencia entre lo que ellos predican y sus acciones. Esto lo lleva a afirmar que, en las condiciones actuales, considerando los errores cometidos, era muy dificil terminar con la guerra en Chile.

En este amplio aspecto de arbitrariedades instaurado para los corruptos "servidores" de S.M. están los atentados a la vida, a la dignidad humana y la imposición de un sistema de explotación del indígena, que derivaría en la esclavitud y, en definitiva, en la negación de todos sus derechos naturales. Una extensa relación recoge Pineda y Bascuñán en esta serie de atropellos a la dignidad humana que van desde los azotes, los cortes de cabellera, de narices y orejas, los raptos de niños, los robos a los bienes de los indígenas, las violaciones a manos de sacerdotes en las propias iglesias, etcétera.

Al plantear Pineda esta problemática de extrema degradación nos describe un mundo al revés, en donde quienes verdaderamente deben encarnar los valores morales de la civilización que representan, aparecen como salvajes. Por su parte, los indígenas, supuestos bárbaros, se nos presentan dispuestos a aceptar y a vivir los principios morales y cristianos que se les proponen. Aquí sin duda está implícita la defensa del indígena, esta es la finalidad de la denuncia y, por esta razón, es que Pineda juega con las antinomias.

Según Chang-Rodríguez, en Violencia, y Subversión en la prosa colonial Hispanoamericana, señala que "usando la estrategia del enmascaramiento para distanciarse de los hechos, el autor se vale de diálogos con los viejos caciques para presentarlos como ejemplos de moderación y sapiensa en obvio contraste con el comportamiento y ambiciones de criollos y españoles. En estas charlas el cautivo escucha con atención las relaciones indígenas que siempre corroboran su punto de vista" (Chang-Rodríguez, 1982).

En la segunda parte de esta fase final, Pineda expone que no es solamente en los indígenas que opera este sistema de arbitrariedades que ha instaurado la administración gubernamental, sino que, también en aquellos nobles y esforzados soldados que han servido en forma honesta la causa de S.M. Compara a los que verdaderamente han desarrollado su oficio con esmero, sin ser reconocidos, y otros, que sin hacerlo, tienen fortuna y son recomendados para asumir puestos de importancia.

A partir de esta denuncia, que hace Pineda por la falta de estimación por el oficio y los servicios que realizan los buenos soldados, Correa (1965) afirma que: 
El ejercicio de las armas se presenta falto de estímulos para el grupo de más valor en la sociedad chilena. 'La fuerza oponente al enemigo tradicional aparece así quebrada en su columna vertebral'. Sin embargo, a pesar de lo apremiante que es su situación personal de soldado desposeído, también, obedeciendo a su condición natural de "caballero de noble origen", hace explícita su preocupación por altos intereses "Bascuñán une al sentimiento de verse postergado el temor por la suerte futura de la patria, cuya pérdida cree posible dado el escaso interés que demuestran los gobernadores en su conservación y progreso" (Correa, 1965, p. 66).

Respecto de la segunda función, Castiglione postula que el gobierno ideal es la monarquía, el que se sustenta en dos grandes principios. La obediencia al príncipe y Dios como el rey ideal del mundo. Ahora, si la persona en la que recae el poder no posee los atributos necesarios, es tarea del cortesano instruirlo y asesorarlo tanto en su formación cortesana como en las tareas gubernamentales. Si este príncipe, para poder gobernar en forma justa, debe ser un perfecto cortesano, entonces, concluimos que este es tanto o más virtuoso que el rey; por tanto, el cortesano sería el modelo ideal de gobernante.

En este mismo afán vemos a Pineda, primero informando de toda una situación sociopolítica contingente, y luego proponiendo preceptivamente una forma ideal de gobierno.

Esta intencionalidad se hace patética a partir del anhelo de verosimilitud que anima a su discurso. A propósito de esto Chang-Rodríguez (1982) dice: "Su insistencia en la verosimilitud funciona como mecanismo de la estrategia del discurso del poder pues presenta al autor como caballero ejemplar, leal súbdito de la Corona y docto escritor distinguido por la autoridad de su conocimiento".

\section{EL PROBLEMA DE LA GUERRA}

Una vez que Pineda ha cumplido con su primera función de decir la verdad al monarca mediante 1a denuncia realiza un minucioso análisis, en forma intercalada, acerca del problema de la guerra en Chile. Reflexión que tiende a ocultarse en las aventuras del cautiverio. Respecto de la confrontación en Chile, Pineda señala que la guerra y la esclavitud son injustas, considerando esta última ilícita y mal usada.

Junto con la esclavitud lo que ha ayudado a incitar aun más la guerra entre araucanos y españoles es la forma en que estos han impuesto la religión. Frente al problema de la guerra injusta, Pineda plantea varias soluciones, entre estas menciona la guerra justa, fundada en un principio de autoridad verdadera, la causa justa, que implica coger las armas siempre y cuando exista alguna culpa que merezca pena o castigo. La tercera razón señala para que la guerra sea justa es que la intención de los que guerrean sea recta y bien encaminada y lo dañoso se evite.

De acuerdo con estos razonamientos Pineda señala que no existen razones valederas para entablar la guerra a los indígenas, ya que estos estaban quietos y pacíficos en sus tierras. Como la guerra es injusta se justifica la reacción natural de los indígenas. 


\section{EL PROBLEMA DEL GOBIERNO}

Una vez que Pineda ha orientado al príncipe en las cuestiones que conciernen a la guerra, procede a revisar el sistema de gobierno y a presentar un modelo ideal de administración, pauta bajo la que debería desempeñar sus funciones el régimen imperante.

Para explicar cómo debe ser el buen gobierno critica los procedimientos usados por Pedro de Valdivia quien aparte de los altos tributos se quedaba con gran parte de ellos. Partiendo de este ejemplo negativo de cómo no se debe gobernar, Pineda establece las condiciones que debería tener el buen gobernante:

porque los príncipes que gobiernan, y está a su disposición y cargo entablar tributos y pensiones, ignoran los inicuos señores que tienen potestad y el mando, que mientras más tributos y cargas ponen a sus ciudadanos, mayores daños y ruinas acarrea para su pueblo o para su reino (Pineda y Bascuñán, 1982, p.132).

Aquí sin duda están presentes en Pineda y Bascuñán las ideas del bien común y del servicio público. Esta es la lectura que hace Correa en su estudio. Para Pineda el gobernante ideal encuentra su símil en Cristo a quien él llama "supremo juez" y "maestro" y cuyo gobierno debiera ser imitado y seguido. En esta perspectiva, según Anadón (1974), está la tesis del Cautiverio, él afirma "que para gobernar bien se necesita una reforma moral según estrictos principios cristianos".

En síntesis, las razones de fondo, según Pineda, de los malos gobiernos se deben, por una parte, a que la mayoría de los gobernantes de Chile han sido extranjeros que no han fundado su mandato en principios morales y religiosos y, por otra, a la primacía del interés personal de enriquecerse a costa de la explotación de los araucanos. Corroborando esta afirmación recreamos la visión directa de Pineda en torno al problema: "De ninguna suerte se avienen bien los forasteros con los ciudadanos naturales: y verdaderamente que los más que han venido a gobernar este remoto reino, parece que lo han sido, pues le tienen en tan miserable estado como en el que hoy se halla" (Pineda y Bascuñán, 1982, p.169).

En definitiva, Pineda postula como solución al problema del gobierno y de la guerra, la urgencia de que sean los chilenos los que se gobiernen y no los forasteros: "fuese saludable ante todo para su patria algún natural experimentado hijo de ella, que no sin misterio grande mandó Dios que no se pudiese nombrar rey o superior, sino fuese de entre los propios hermanos y compañeros" (Pineda y Bascuñán, 1982, p.169). De este modo, indirectamente, se está acreditando como un virtual gobernador ideal. Es él, el que cumple con todos los requisitos y las virtudes para asumir el mando político en Chile, avalado por su condición y calidad personal de perfecto cortesano; es él quien denuncia las injusticias de que eran objeto los indígenas, colocando en evidencia las falsedades de las crónicas aduladoras y los malos gobiernos de los gobernadores extranjeros. Y, finalmente, es el que propone un sistema de administración política inspirado en la religión y en la figura de Cristo, principios que él ha asumido como 
normas en su vida. Por tanto, acreditándose de tal modo, sería el único criollo apto para gobernar Chile, propósito que queda embozado en la "falsa modestia" con que plantea su proyecto de escritura a Carlos II:

Porque mi intención no ha sido llevada de otra cosa que de la razón, de la justicia y del celo fervoroso de manifestar y dar a entender a su Real Majestad, con claras y patentes verdades, las causas y fundamentos que hay para que su reino de Chile se le pierda y consuma brevemente, y le estén gastando su patrimonio real sin fruto ni provecho ninguno, como más largamente queda manifiesto en los atrasados renglones, y como la guerra y conquista de este reino es perpetua e inacabable (p. 169).

\section{OBRAS CITADAS}

Anadon, José (1974). Tres notas sobre Pineda y Bascuñán, en Revista Iberoamericana $\mathrm{N}^{\mathrm{o}}$ 86, Vol. XL Enero-Marzo: 111-118.

Castiglione, Baltazar (1994). El Cortesano, Madrid: Cátedra.

Correa, Sergio (1965). El Cautiverio feliz en la vida política chilena del siglo XVII. Santiago: Andrés Bello.

Chang-Rodríguez, Raquel (1982). Violencia y subversión en la prosa colonial hispanoamericana, siglos XVIy XVII. México: Porrúa.

Mignolo, Walter (1982). "Cartas, crónicas y relaciones del descubrimiento y la conquista", en Madrigal, Luis Íñigo (coord.) Historia de la literatura hispanoamericana. Tomo I Época colonial. Madrid: Cátedra, 57-116.

Núñez de Pineda y Bascuñán, Francisco (1982). Cautiverio Feliz, Santiago: Editorial Universitaria, Segunda edición. 